\title{
A Multi-dimensional Analysis of Booming E- commerce (Online Shops) in Urban Villages
}

\section{A Case Study in Tongcun}

\author{
Haochen SHI, School of Architecture, South China University of Technology, China \\ Xiaoxuan CEN, School of Architecture, South China University of Technology, China \\ Yanjun LAI, School of Architecture, South China University of Technology, China
}

\begin{abstract}
In the past decade, E-commerce has thrived with the popularization of the Internet and it not only has changed people's daily life, but also has generated a new urban form. Driven by the low entrance standard and flexible work location of 'Taobao' (a C2C E-commerce company like eBay), e-commerce brings to life a range of burgeoning startup SMEs in urban villages where business cost is low and transportation is convenient. This article does an in- depth case study of the Tongcun village in Guangzhou to explain this special business ecosystem. By giving comprehensive illustrations and conducting a SWOT analysis of the online shops, the article points out the flexibility and resilience of community network. Meanwhile, it also demonstrates the restriction and instability of this special business ecosystem.
\end{abstract}

\section{Keywords}

E-commerce, Urban Villages, SWOT Analysis, China

\section{Background Introduction}

\subsection{E-commerce and The Appearance of Urban Villages}

Since the turning of the 21st century, China's e- commerce industry has entered a period of fast development as a result of the prevalence of the Internet and China's robust economy. (Yao and Tan, 2004). Meanwhile, China's consumption acted as a more significant driving force for the economy and it has gradually replaced the economic status of investment, which used to be the most important pillar of Chinese development (Britton, 2010). Therefore, China's e-commerce has already become a vital pillar of China's consumer market (Yang, et al., 2011).

During the same time, with the rapid speed of urbanization, large numbers of urban villages have occurred in the southeast developed areas in China, especially in metropolis (such as, Guangzhou and Shenzhen) located at delta of Pearl River (Herrle, et al., 2014). One of the reasons for their formation is that rapid urban development causes cities to encroach on rural areas (Hao, et al., 2013), resulting in a phenomenon, "villages surrounded by cities". The other reason is that villagers' house sites survive during this encroachment because Chinese land system protects farmers from losing their houses' sites to capital invasion (Pu, et al., 2013). Nevertheless, deprived of their farmlands, residents of Guangzhou's 138 urban villages have no choice but to build more houses on their house sites for rent money (Zhang, 
2005; Song et al., 2008; Tian, 2008; Chung, 2009). However, the abundance of cheap rental houses not only accommodates hundreds of thousands of workers, but also provides entrepreneurs with office and factory space, laying a good foundation for emerge of Tongcun (figure 1).

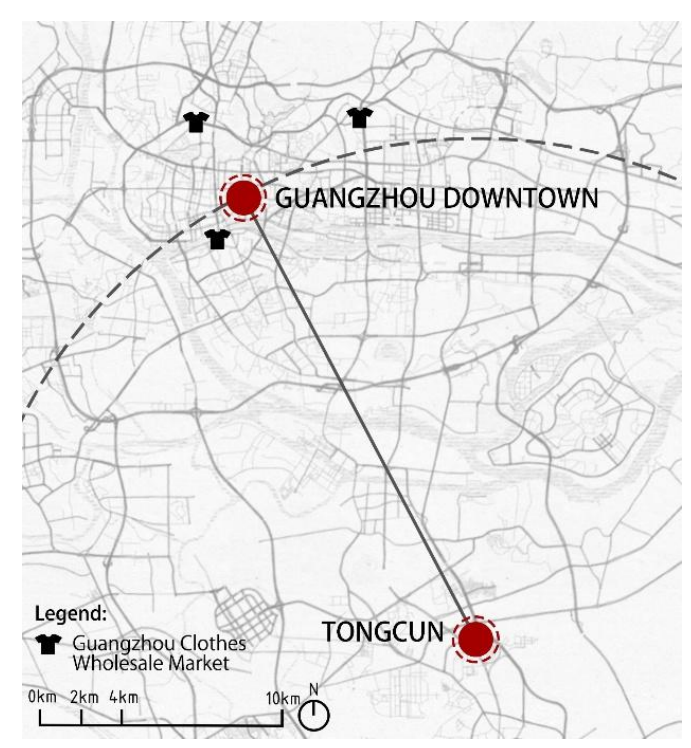

Figure 1: Location of Tongcun

\subsection{Information about Tongcun village}

Located in Nancun Town, Guangzhou, Lirentongcun village (referred to as Tongcun in the following passage) has been called Taobao village since it became the home base for a large amount of Taobao online shops. In December 2013, Tongcun was listed as one of the "20 Emerging Taobao villages in China" (Ali Research Center, 2013).

In addition, the main product that online shops in Tongcun sell is clothing. At the peak, nearly 40 percent of the buildings were occupied with online shops. Now, due to the sluggish economy, the number of the online shops decreased from 1000 to 500 (He and Li, 2014). Moreover, Tongcun has successfully formed its own special economic system, which can be described using a comprehensive value chain model (figure2).

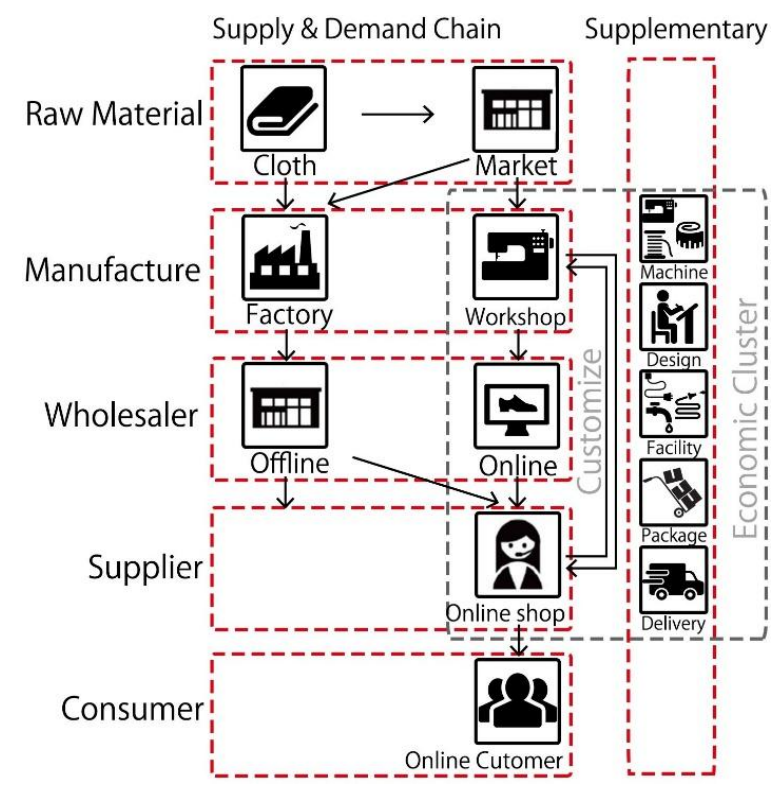

Figure 2: chain model 


\section{Methodology}

The method we using to analyze is SWOT Matrix, which is widely introduced into various subjects and projects, especially in management. Actually, SWOT is an acronym for strengths, weaknesses, opportunities and threats (New Oxford Rhyming Dictionary, 2012) and is a well-organized method that assess these four aspects of business activities or plans (The AMA Dictionary of Business and Management, 2013). The essay will regard Tongcun as a special enterprise to analyze its four fundamental elements, and subsequently give some suggestions of the improvement of such a special but vital business ecosystem.

\section{SWOT Analysis of Tongcun}

\subsection{Strength Analysis}

\section{Strength of Community network}

Mainly consisting of Chaoshan people (Chen, 2002), the community of online shops owners builds up a close-knit network of cooperation, which is based on the compatriot connection and working relationship (Song and Ma, 2015). This "fellow-village community" network sets up a virtuous circle (figure 3) for the development of online shops. At the beginning, for online shops do not require many staff, they usually start with small-scale businesses and most of their staff are family members. As time going by, when these online shops expand, they prefer to recruit relatives or fellow-townsmen from home. This mainly caused by the fellow-village emotions which make them have more faith in one another and consequently be more likely to work together (Song and Ma, 2015). At the same time, in order to develop, the online shops gradually tend to integrate themselves into the community network which is simple to join in because they are all Chaoshan people. As for the benefits of the community, firstly it can keeps bringing new investors and workers into the village. In addition, some online shops can also acquire some inventory information from the community network, which might increase the diversity of goods and reduce the risk of inventory surplus. Furthermore, because of the tradition of sharing, the process of adaptation is highly compressed. People from the same origin, which is usually the case, are more likely to fit in. For example, the main language used among shop owners is Chaoshan dialect, instead of Cantonese which is spoken by native villagers. All these advantages can attract more new Chaoshan businessmen into these community networks and automatically enlarge Tongcun.

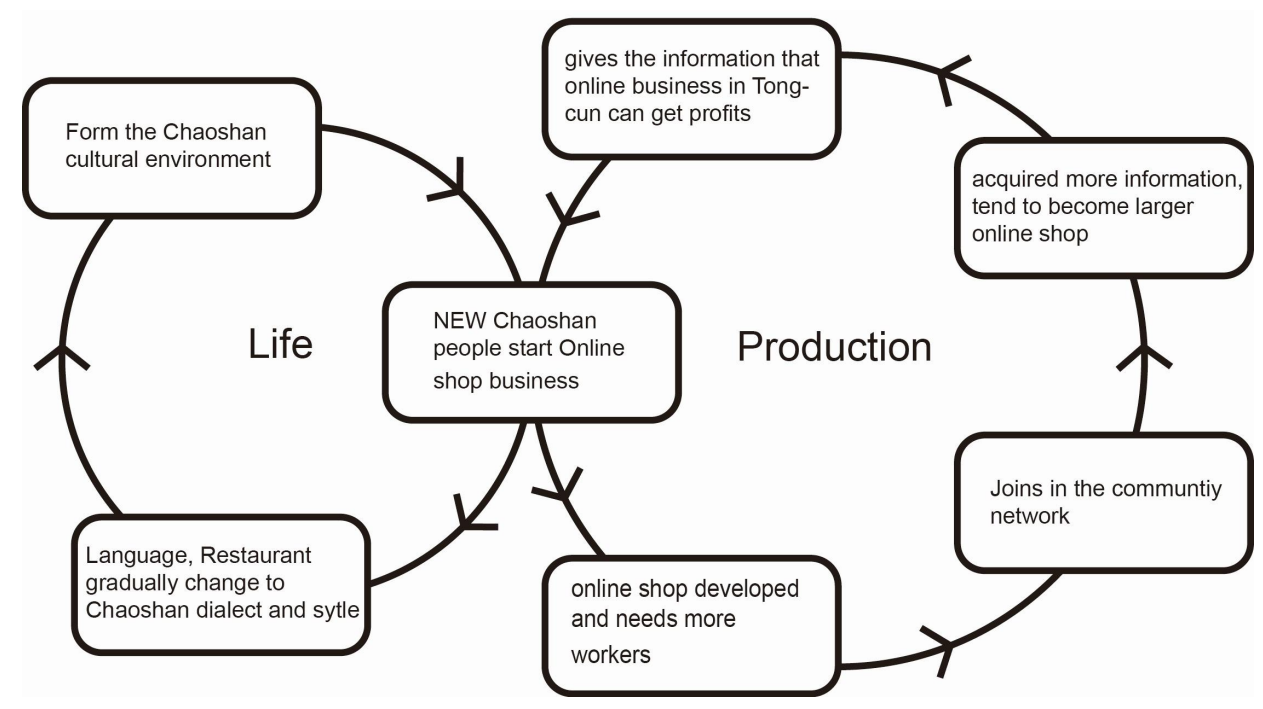

Figure 3: Virtuous circle in Tongcun

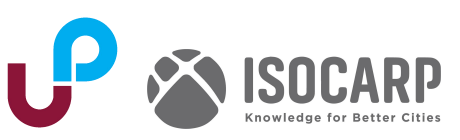




\section{Strength of Agglomerate economy}

Agglomerate economy enlarges benefits that firms obtain by locating near one another, which is related to economies of scale and network effects (Brendan, 2005). As more firms in related fields of business cluster together, their costs of production may decline significantly. Gathering online shops and related industry, Tongcun, which can be referred to as localization economies, has three benefits brought about by the Agglomeration economy.

The first benefit is labor market pooling. Large groups of laborers enter the area and are trained to become skilled staff or shops owners. The laborers and shop owners exchange knowledge, skills, and information. The labor market pooling also matches labors to labors, labors to shops, shops to shops, which help them find suitable positions. According to our survey, the flows among industries are very common.

The second benefit is the accessibility to specialized infrastructures and services which are just for the clustering business (Marshall, 1920). Agglomerate economy enables the market to respond quickly to the new demands of customers. Until the online shops in Tongcun reach a certain scale, the supplementary industries did appear due to the proximity to available sources needed for production, facilitating the supply chain. It is especially the case in the express delivery companies whose service stations total 14 in this small village. The delivery service (shown in figure 4) of delivery companies is expected to attract more customers by providing convenient service while reducing the cost of transportation. The competition among the delivery companies leads to lower delivery price which further benefits online shops.

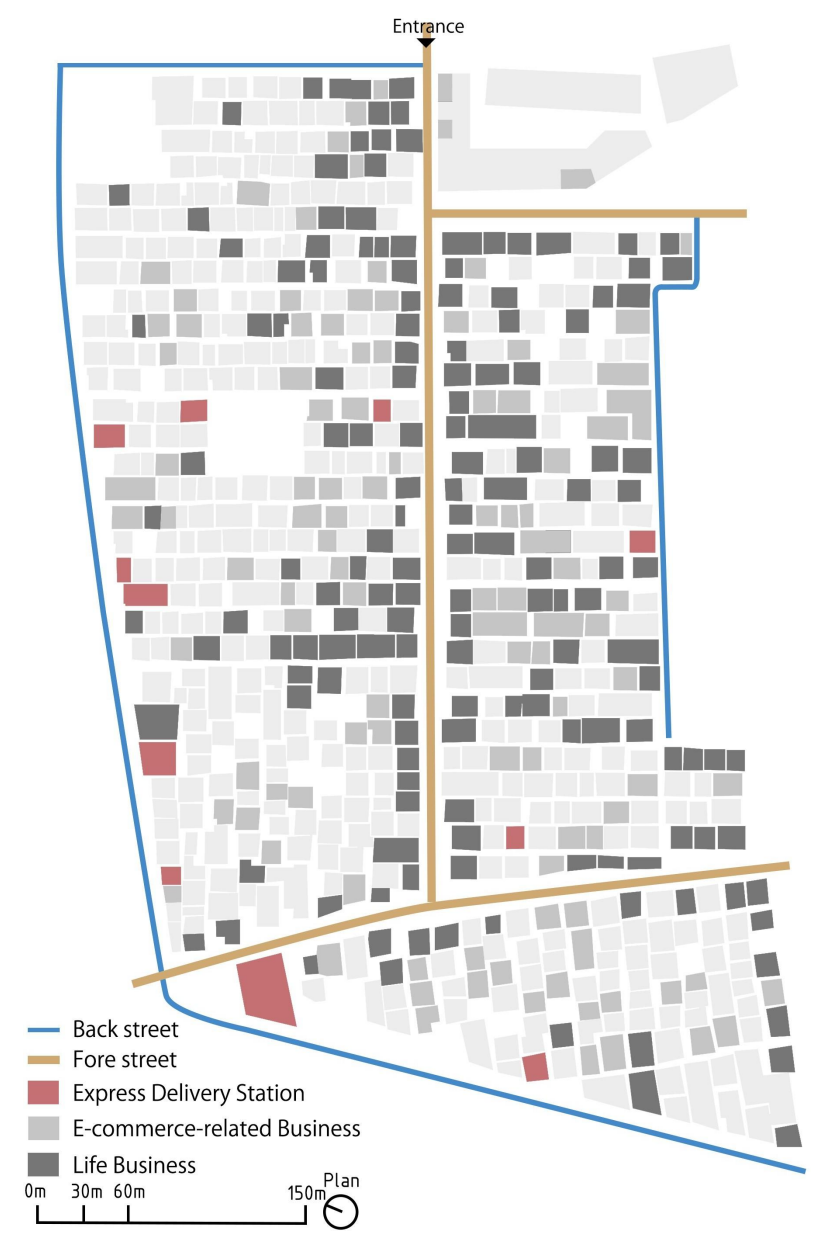

Figure 4: delivery station map

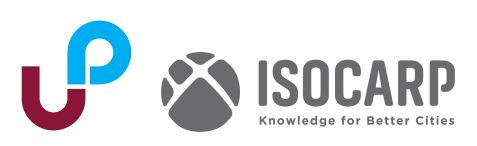


The third benefit is the knowledge spillovers (Brueckner, 2011; Cainelli, 2008). Clusters in specific fields lead to quicker spread and adoption of ideas as well as the wide spreading of knowledge and skills. In addition, experience exchanging among shops disperses explicit knowledge, including sources of commodities and approaches to entering the supplementary industries and so on. But most knowledge in running online shops is tacit knowledge that cannot be easily told, like marketing knowledge and service skills. For example, the skills of concluding consumer's preference from online comments and feedbacks cannot be easily taught because they require comprehensive assessment and judgment ability. Through the exchange of these knowledge within and between shops, it is more easily for them to keep themselves updated in the village.

It is usually the case that when companies in the same cluster compete with each other, vicious competition often causes damages (Liu, 2009). However, the case of online shops in Tongcun is superior to other cases in that when it comes to online shopping, information of commodity is more transparent, leading to less need for competition. Shops do not need to compete with shops in the same region because all the commercial activities are operated online (Zhang, 2015).

\section{Strength of Mixed-use space}

The mixed-use space (figure 5) reflects the dynamic demand of the industry chain, which is applicable to the small scale of production in Tongcun. Though the living quality is less than satisfactory, the conjunction of the multiple functions largely saves time and space. According to a survey from Yangcheng Evening News (2010), the average length of commute route of Guangzhou residents is 15.16 kilometers,

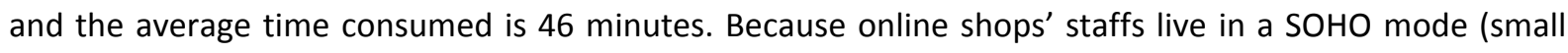
office \& home office), they promote the efficiency of the business by saving commute time and cost.

Meanwhile, the characteristic of mixed-use space also enhances the flexibility of resource distribution, which may be very likely lead to better market arrangement. Mainly controlled by rent prices, every floor of the buildings in Tongcun is susceptible to the influence of the capital market. Due to the industrial mode of online shops, commercial functions can be easily spread to the housing sector, allowing more freedom in the leasing market. Under this mode, the distribution of space is more easily to approach the ideal rent curve where all sectors are controlled by people's ability to pay rent based on market principles.

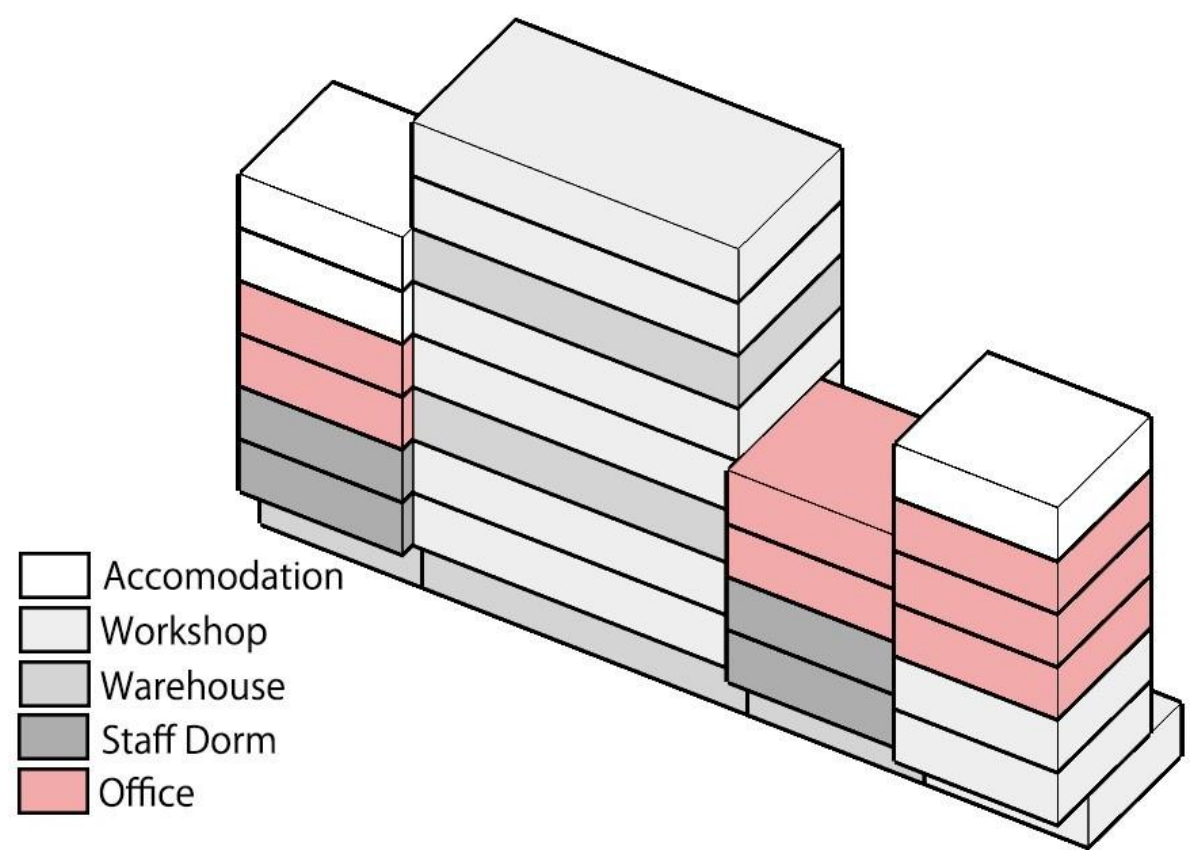

Figure 5: Mix-used space 


\subsection{Weakness Analysis}

\section{Passive cooperation from the local community}

Before the appearance of e-commerce in Tongcun, the local community were mainly concerned about security, sanitation, and transportation when constructing new residents. During the period of rapid rise of e-commerce, the local community tried to evade the responsibility of upgrading the infrastructure, which has already met the residential need. The original villagers, as the owners of the buildings, do not care about renters' identifications as long as they pay their rent-on time. Since the rent alone can cover the living expenses of a common villager's entire family, those villagers do not show much interest in joining the e- commerce business. Furthermore, due to difference in daily routines between businesspeople and residents, some of the native villagers' interest conflict with that of online shops.

\section{Limits of further development}

For some outsiders who are unfamiliar with the traditional business of clothing and lacking in social network, to survive in the capital market is hard. Usually, the beginning stage of an online shop is fragile. Except for the starting fund and facilities, some of the shop owners also have to hedge against the risks of market investment failure. Because of lacking of credits, most of these shops went out of business after investment stop flowing in. There are almost no credits or related policies when it comes to online business. However, I came across a lot of advertisements for underground banks in Tongcun, providing illegal aids to shop owners and in turn proving that there is need for such banks.

In Tongcun, online shops that sell clothes usually start by replicating styles of other shops' clothing. After purchasing identical clothes of certain popular brands produced by manufactories or workshops, the shops tag them with their own brand and then sale. Such plagiarism of intellectual property greatly reduces the risks of choosing the wrong styles or the cost of designs. Though helpful at the beginning, this practice will not help business move to a more advanced stage where shops are required to develop their own brand if they want to promote sales by expanding brand impact (AliResearch, 2015). Besides the brand promotion, upgraded clothing shops cannot always depend their production on small workshops in the village. They should go to professional manufactories instead. In order to develop their brand design team and continually produce large amount of clothing, large-scale and productionqualified space is imperative, but that is something that Tongcun cannot provide. Most of the online shops leave the village once they grow into professional clothing companies.

\subsection{Opportunity Analysis}

\section{Brand upgrade}

As consumers become more and more rational with online shopping, they call for better shopping experience as well as information symmetry in commodities' quality, price of commodities and customer service. Pursuing high price-quality ratio, customers' demand is the top concern in a good market environment where information is transparent. Under this circumstance, shop owners have to promote its brand reputation to ensure their foothold in the market. In 2013, in order to encourage brand upgrading, Taobao opened a sector for original 'Tao' brands, which set entering limit for qualified small business to come in. This move mended, to a great degree, the small shops' image of being counterfeiters and changed the common attitude towards small brands for the better. Consumers of low purchasing power are very willing to purchase commodities from 'Tao' brand sector. In Tongcun, online shops were given direct access to workshops and design studios to promote brand-building. However, the resources village-wide cannot meet the demand of building 'Tao' brands. It is a great opportunity for bigger shops to cooperate with companies outside in order to build their brand image.

\section{Industrial transformation}

\section{U isocarp}


Due to knowledge spillover effect, some shop owners like Luo discovered the new field of e-commerce's downstream industries, like skill training institutions and information platforms for jobs and inventory. According to Smiling Curve theory (Lu and Xia, 2010), the upstream and the downstream of the value chain have more potentials to create extra value. Owning to the large number of online shops that are still expanding, it is of potential prospect to invest in the service business of online shops. Listed among the top Taobao villages, Tongcun has the most mature industrial foundation, which means it can offer downstream service in larger context. Recently, Luo also put efforts in expanding his service from regionwide to citywide, from one type of commodity to various categories.

\subsection{Threat Analysis}

\section{Market condition threat}

In order to avoid the situation where shops disrupt market fairness, including practices of copying images from other shops, selling counterfeit, fabricating customers' comments, and tarnishing other shops' reputation, Alibaba has been perfecting its regulations for a while. Startups that do not meet the requirements will be washed out. For example, one of the vital rules is the consequence of the search results, which can, by and large, influence the sales volume of the shops. Choosing different priority, customers can get different results searching the same keyword. In 2011, the most chosen search priority was sales volume. So, the common strategy of less popular shops is through buying their own commodities to increase their sales volume (Liu and Xia, 2010).

Online shops of Taobao, represent the trend of common civilians' entrepreneurism. However, being amateurs, most of them cannot compete with big shops, especially for newcomers to the world of business. Forbidden from exploiting online regulations for their benefit, most small shops can hardly stay open. In 2012, Alibaba opened a new branch firm called Tmall, which promised customers high quality commodities and superb service. The entrance threshold for opening shops in Tmall is relatively high for small online shops. Since lots of consumers want to buy qualified goods, Tmall has gained big market share from Taobao, damaging the profit of Taobao's shops.

\section{Rising rental cost}

As owners of the buildings, native villagers are mainly concerned about how to maximize their profits by charging higher rent, no matter who the renters are. At the beginning, online shops chose Tongcun to settle in mainly for the reason that its rent is comparatively low and that the traffic is convenient due to its proximity to urban area. However, development of surrounding areas recently increased the land value. Large outlet malls and massive residential areas also increased the demand for additional housing to accommodate the incoming laborers employed in the service industry. Also, the improved living environment makes people more willing to live in Tongcun where they can have access to urban convenience but don't have to pay for an urban apartment that they usually cannot afford. As a result, the online shop owners are struggling with the area's rising housing demand. The rent increases with the rising housing demand to the price that some of the newly opened shops cannot afford. After weighing the profits against the cost, they quit.

\section{Conclusions and Discussions}

The essay analyzes booming E-commerce (online shops) phenomenon in Tongcun through SWOT Matrix and clearly illustrates the advantages and shortcomings of this special business ecosystem. Actually, with the growth of Chinese e-commerce and urbanization, many online shops have occurred in urban villages and Tongcun is one of the most typical case (Tan and Tan, 2014). In China, urban villages are always labelled as "poor" and "undeveloped area" (Herrle, et al., 2014), but this special urban form successfully 
generates many special and vital activities that could never be developed in western countries. Therefore, from the viewpoint of urban planning, this energetic business ecosystem can provide us some precious experience when the authorities build an economically-sound and spontaneously-formed system within the E-commerce industry. For example, Tongcun's case shows the importance of having a community that is a mature social network of online economic system (Tan and Tan 2014). In addition, these selfdeveloping business ecosystems should also be protected as they give some possible future of urban villages. Thus, to ensure the sustainability of the Taobao economy in Tongcun, the essay suggests that government should protect the social and economic network of Tongcun through better institutional designs. However, there are still few restrictions in the essay. Firstly, some experts believe this special ecosystem is somewhat a "freak" of Chinese economic development and they will eventually become a sand of history. Moreover, the method the essay puting forward needs to be more specifically discussed. To conclude, the essay demonstrates the business ecosystem in Tongcun from various perspectives (based on SWOT analysis) and tries to appeal for protection of such ecosystem.

\section{References}

Oxford Language Center (2012) New Oxford Rhyming Dictionary, Oxford: Oxford University Press.

Ali Research Center (2013) 20 Emerging Taobao villages in China, Hangzhou.

Ali Research Center (2015) 20 years Expasion of E-commerce: Revolution and Transformation, Hangzhou: AliResearch.

Brendan, O. (2005) City Economics, London: Harvard University Press.

Britten, E. (2010) Consumption: New Key to Chinese Growth. China business review, pp.26-29.

Brueckner, J. (2011) Lectures in Urban Economics, 1st ed. The MIT Press.

Cainelli, G. (2008) Spatial agglomeration, technological innovations, and firm productivity: Evidence from Italian industrial districts. Growth and Change, (39), pp.414-435.

Chen, Y.Y. (2002) Effect of Geographical Factors on Chaoshan Traditional Culture. Journal of Shantou University, (04), pp.71-76.

Chung, H. (2009) A planning of "villages-in-the-city" in Shenzhen, China: the significance of the new stateled approach. International Planning Studies, 14.3, pp.253-73.

George, T.K. (2013) The AMA Dictionary of Business and Management, Publishing Division of the American Management Association.

He, D.L. and Li, X.Y. (2014) Reveal the Secret behind Tongcun. Guangzhou Daily, 11th October,

Liu, X.N. and Gai, Z.J. (2012) B2C E-commerce Standardized Development: From the Sight of 2012 Taobao New Rule. Journal of Chifeng University (Natural Science Edition), (04), pp.33-42.

Liu, Y. (2009) 'Study on Corporation's Circular Economy Behavior of Manufacturing Agglomerate Region'. China Population Resources \& Environment, pp.55-64.

Lu, N.J. and Xia L. (2010) Interpretation of Smiling Curve Theory, Journal of Southeast University (Philosophy and Social Science), (03), pp. 175-182.

Marshall, A. (1920) Principles of Economics, 8th edn., London: Macmillan.

Peter, H., Josefine, F. and Detlev, I. (2014) Beyond Urbanism: Urban(izing) Villages and the Mega-urban Landscape in the Pearl River Delta in China. Berlin: Lit Verlag Fresnostr 2. 
Pu, H., Stan, G., Pieter, H. and Richard, S. (2013) Spatial Analyses of the Urban Village Development Process in Shenzhen, China. International Journal of Urban and Regional Research, 37.6, pp.217797.

Song, Y., Zenou, Y. and Ding, C. (2008) Let's not throw the baby out with the bath water: the role of urban villages in housing rural migrants in China. Urban Studies, 45.2, pp.313-30.

Song, Y.P. and Ma, T. (2015) Influence of Fellow Association to the Income of Rural Migrant Workers. Journal of Renmin University of China, (02), pp.125-131.

Tan, L.Y. and Tan, L.W. (2014) Taobao Village Enlighten the Rural Development in China. China State Finance, (20), pp.89-97.

Tian, $L$ (2008) A chengzhongcun land market in China: boon or bane? The perspective on property rights. International Journal of Urban and Regional Research, 32.2, pp.282-304.

Yang, J., R. Wang, R. Zhang, and L. Li. 2011. (2011) Analysis of the Investigation on the E-commerce Application Status at Different Regions in China. Observation E-business Journal, 11, pp.7-8.

Yao, Y.M. and Tan, J.Z. (2004) Transformation of Urban Village in Guangzhou. Planners, (05), pp.67-82.

Zhang, L (2005) Restructuring the Chinese city: changing society, economy and space. New York: Routledge.

Zhang, Z.W. (2015) Competitiveness of Industrial Cluster of E-commerce. Journal of Ningbo University, (03), pp.112-134. 